\title{
STUDENTS' FIRST APPROACH TO READING COMPREHENSION: PRE-READING STRATEGIES
}

Xinia Chacón Arce Universidad Nacional, Costa Rica

The main objective of a reading class is not translation but comprehension. To develop the reading comprehension skill in another language, it is necessary to teach students how to approach a text using reading strategies. There are pre-reading, in-reading, and post-reading strategies. The purpose of this article is to present pre-reading strategies.

Oxford defines language learning strategies as specific actions, behaviors, steps or techniques students use to develop second or foreign language skills. These strategies are significant to students because they help in the internalization, storage, retrieval or use of the new language. Besides that, students get involved in the learning process by themselves. When they learn how to handle a situation and solve it using strategies, they feel very motivated and willing to learn more, so strategies make language learning quicker, easier, more effective, more fun, more self-directed and more transferable to new situations. ${ }^{1}$

Pre-reading strategies are those strategies applied before a careful reading of the text is done, and they are essential because they facilitate

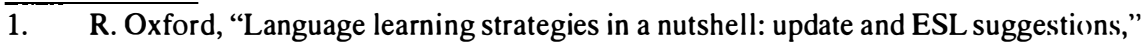
Tesol Journal, 2, 2 (1992/1993) 8. 
comprehension which in turn gives students self-confidence. According to Shih, these strategies help activate and exploit the background knowledge of readers, add motivation, expand curiosity, imagination and concentration. They also give students a purpose for reading, hints on the organization, and the basic content of the text (establishing the topics and sub-topics of the content to be covered). ${ }^{2}$ This knowledge on basic content is vital for in-depth comprehension and recall as mentioned by Hirsch and Gabbay. ${ }^{3}$

This paper presents the following pre-reading strategies to prepare students for a reading comprehension class: development of background knowledge, previewing, guessing, skimming, scanning, structure presentation, and vocabulary preparation. The following text will be used to illustrate the strategies. It was taken from a brochure published by the American Heart Association. ${ }^{4}$

The texts teachers use in an English reading comprehension class must fulfill certain characteristics to be motivating for the students. They have to be authentic; this means that the text must not be modified to fit the students' level of reading competence, but as it is found in any real-life material. It should not be very long. Long texts result tiring and boring, even if the topic is interesting. One page or a page and a half is an adequate length for teaching. It has to be complete. It is not a good idea to use the introduction of a chapter; for instance, because the topic is not fully developed and the tone, purpose and attitude of the author-among other features - will not be reflected in a piece of text. The instructor should never typewrite a text to hand it out to the learners. It is better if the reading is a photocopy of an original text, so that the students feel they are working with authentic material,

2. M. Shih, "Beyond comprehension exercises in the ESL academic reading class," Tesol Quarterly, 26, 2 (1992) 289-311.

3. S. F. Hirsch \& A. Gabbay, "A current events approach to academic reading," Tesol Journal, 4, 4 (1995) 27-30.

4. American Heart Association. The American Heart Association diet: an eating plan for healthy Americans [Brochure], Texas: National Center, 1991. 


\section{Eating Plan Tips}

To control the amount and kind of fat, saturated fatty acids, and dietary cholesterol you eat:

- Eat no more than 6 ounces (cooked) per day of lean meat, fish and stintess poultry.

- Try main dishes featuring pasta, rice, beans and/or vegetables, Or create "low-meat" dishes by mixing these foods with small amounts of lean meat, poultry or fish,

- The approximately 5 to 8 teaspoon servings of tats and olls per day may be used for cooking and baking, and in salad dressings and spreads.

- Use cooking methods that require litte or no fat-boil, broil, bake, roast, poach, steam, saute, stir-iry or microwave.

- Trim oft the fat you can see before cooking meat and poultry. Drain of all fat atter browning. Chill soups

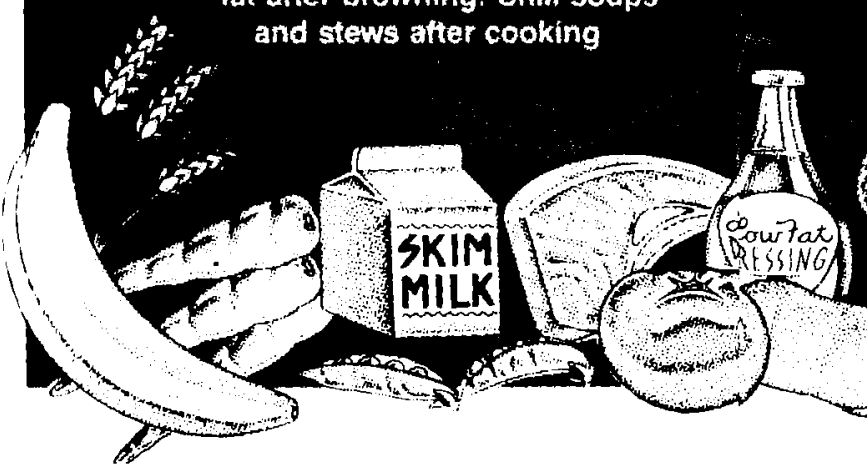

so you can remove the hardened fat from the top.

- The 3 to 4 egg yolks per week included in your eating plan may be used alone or in cooking and baking (Including store-bought products).

- Limit your use of organ meats such as tiver, brains, chiterlings, kidney, heart, givard, sweetbreads and pork maws.

- Choose skim or $1 \%$ tat milk and nonlat or low-fat yogurt and cheeses.

To round out the rest of your eating plan:

- Eat 5 or more aervings of fruits or vegetables per day.

- Eat 6 or more servings of breads, cereals or grains por day.

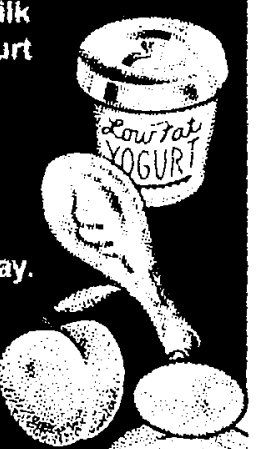


and can appreciate the different types of layout and organization. At the same time, they will also feel free to work on it. They can write, take notes, make annotations, draw arrows and circles, underline, etc.

Another crucial aspect to be taken into account when finding texts to bring to class is the topics. One way of selecting them is to do a short needs assessment by means of oral questions or a short questionnaire to find out which themes the students prefer. Another way is to ask them to bring to class readings related to their favorite topics, and use them in class. It is hard to fulfill all the students' needs in regard to the topics they want to read. Even if the teacher tries to investigate about their likes and dislikes, it is hard to please everyone in the same class period because the reading a student brings to class may or may not be interesting for the rest of the classmates. This is why it is a good idea to provide the space for the preparation of portfolios in which learners can develop a project based on their individual interests and reading purpose. In any case, universal, interesting topics will work just fine for the class work.

The development of background knowledge or the idea of using your previous experience and knowledge to approach the text, and being able to infer information from the passage because of this information the reader already has, is one of the paramount strategies for reading comprehension. At this point the reading has not been handed out to the students yet. This strategy can be done by asking students what they know about the topic of the passage. In the case of the brochure reading the teacher can ask: What do you know about cholesterol? Do you know of any person who suffers from high levels of bad cholesterol? Have you ever heard of its effects? Is there any solution for that? If some students know about the topic the instructor encourages them to share their knowledge with the rest of the class, and s/he can just prepare activities to enhance the class' knowledge. Anderson suggests that teachers give a mini-lecture about the topic if nobody participates to facilitate the success of the comprehension activities that will follow later. ${ }^{5}$

5. N. Anderson, ExploringSecond Language Reading: Issues and Strategies (Washington: Newbury House, 1999). 
Another activity to develop background knowledge is through a film. To integrate film and text teachers should use criteria such as: a challenging text that does not have an impossible lexis rate, and an interesting and not complex argument; and a film that presents a compatible version with the text, so that students do not get confused; in this way, the topic in both the text and the film will be cognitively and emotionally appealing to the students. In class, the teacher shows the film first, and then asks the students what they know about the topic and what they understood. The instructor will also give the students time to introspect and take some notes about the information they recall from the film before reading the text. Later they skim the text, and keep a notebook with ideas, quotations, or reflections they watched in the movie or read in the text. Hess and Jasper consider that the role of the teacher should then be to make students tie the events of the reading and film to their own experiences. ${ }^{6}$ Instead of a film the teacher can use a poster, proverb, joke, cartoon, or picture that can be related to the content of the text.

Previewing is another pre-reading strategy. This strategy consists of the observation of features. Learners must learn how to preview different types of texts such as: textbook chapters, chapter sections, brochures, encyclopedia passages, dictionary entries, manuals, and journal, magazine, newspaper and Internet articles. Not all the information is equally important, or equally organized. Students should focus on very informative clues such as: title and subtitles, headings, the introductory paragraph(s), highlighted information, numbers, and capital letters. Stoller believes that learners should also notice the layout of the reading such as pictures, charts, graphs, tables, photographs, among others, that may help them guess the main $\operatorname{idea}(\mathrm{s}) .{ }^{7}$ For the brochure presented at the beginning of the paper the

6. N. Hess \& S. P. Jasper, “A blending of media for extensive reading," Tesol Journal, 4, 4 (1995) 7-11.

7. F. L. Stoller, "Making the most of a news magazine passage for reading-skills development," English Teaching Forum, 32, 1 (1994) 2-7. 
student looks at the drawings, the title, the sentences in italics, and the dots that mark the rest of the sentences to figure out what the reading is about. This is the very first approach to the reading.

Guessing is still another strategy. Learners will pose questions or hypotheses to themselves before or while reading the text. They have to ask themselves what the reading will be about and guess just by looking at the layout of the reading and the title, headings and subheadings. For instance, to apply this strategy to the text provided at the beginning of this paper, the learners could just look at the tittle 'Eating Plan Tips', the two subheadings in italics, the dots that give a hint of a list, etc., and ask themselves questions to infer what the content of the text can possibly be about. Another way of doing it is by asking students to propose hypotheses, do a rapid reading (skimming) and confirm or reject those hypotheses the best way they can and with the limited information they have at this point.

A different strategy is to read paragraph by paragraph rapidly, read a paragraph and predict about the information that is coming in the following one. Milne advocates the completion of jigsaw puzzles; for example, the students read a text very rapidly, cut it in paragraphs, scramble them, and rearrange them in orderagain using rapid reading. ${ }^{8}$ This activity allows students to look for clues and guess what comes first and what goes after. Stoller advises teachers to ask learners to write a letter next to each paragraph, and write short phrases about the information included in each one. Then they write these phrases in random order on a separate piece of paper, and ask other classmates to match the phrases and the corresponding letters. ${ }^{9}$

Another guessing question is to ask themselves the author's purpose in writing the text. De Vasconcelos and Santiago propose helping learners guess why the author decided to write the text and

\footnotetext{
$\overrightarrow{8 . \quad \text { D. Milne }}$ "Reading-comprehension material for science students," English Teaching Forum, (1989) 37-38.

9. F. Stoller, 2-7
} 
what his purpose was. ${ }^{10}$ An additional possible guessing question is for the students to ask themselves about the pattern of organization of the passage. Is it listing, time order, comparison/contrast, cause/effect, definition, classification, process, analogy? Knowing the type of organization of the text before a careful reading is done is crucial for the mental organization of the ideas, and consequently for a better comprehension. For this type of guessing activity, students pay attention to any clue at hand (e.g. layout of the reading, title, headings, and subheadings, sentence and paragraph linkers). In the case of the reading 'Eating plan tips', students have to pay attention to the ideas marked by dots that makes it a listing.

The text proposes an eating plan in the form of a list of suggestions. Therefore, they can guess that the pattern of organization of the text is listing.

It is important to mention that students solve all the activities mentioned above after doing a rapid, timed reading only. This is what makes them guessing strategies. Providing more time than necessary would change them into during-reading strategies.

Skimming is another very useful strategy that was already mentioned in the former strategies. Skimming is a type of rapid and silent reading to get the main ideas. The students have to learn how to read very fast without worrying about skipping words. So, the idea is for them to understand some words, but not everything, and to attain a general overview of the passage. The readers will use any tool available to them to understand the text such as cognates (e.g. words similar in English and Spanish), any words they already know, previous knowledge of the topic, and the context itself to figure out the content of the text. Clarke and Silberstein suggest teachers tell students that skimming is helpful to obtain a general idea of a text in cases in

10. J. De Vasconcelos \& V. Santiago, "Designing ESP materials for university students," English Teaching Forum, 30, 4 (1992) 36-37. 
which the reader does not have time to read it slowly or when he wants to decide if careful reading is worthwhile. ${ }^{11}$

Other uses for skimming are to detect key words that should be looked up first in the dictionary. Also, after skimming the text it will be easier to find the right meaning of the words in the dictionary because the reader already has an idea of the topic of the text, and consequently will be able to discriminate a lot better the meaning of the word among all the possibilities in the dictionary entry. Skimming is also helpful to hypothesize about the pattern of organization of the passage. In addition, Hirsch and Gabbay recommend that teachers ask students to skim the first few paragraphs, find the author's thesis, look for evidence the author presents to support his main idea, find out if the evidence is strong or weak, and look for other points of view. ${ }^{12}$

Furthermore, Stoller suggests skimming the first and last paragraphs and the first sentence of each intermediate paragraph to get the main ideas. ${ }^{13}$ After skimming the text, Salwa mentions the importance of writing an outline or semantic map that would show the main points of the content. ${ }^{14}$ The teacher can link the semantic map with the pattern of organization, or the topic of the text. For instance, if the pattern of organization of the reading 'Eating Plan Tips' is listing, start a semantic map by asking the students about the pattern of organization, and the ideas they understood from the list. If the semantic map is done by topic, ask students to give you key words that relate to the topic of the reading, and establish relationships among them. The educator has to remember that the learners are doing their best in providing ideas with whatever information they understood from the text after doing a rapid reading. Leave either semantic map

11. M. A. Clarke \& S. Silberstein, "Toward a realization of psycholinguistics principles in the ESL reading class," Language Learning, 27, 1 (1977) 135-154.

12. S. F. Hirsch \& A. Gabbay, 27-30.

13. F. Stoller, 2-7.

14. G. Salwa, "ESP reading: some implications for the design of materials," English Teaching Forum, 31(4) (1993) 42-44. 
on the board to corroborate the information later when the students read the text more carefully and feel more confident about the content of the passage.

Scanning is another important strategy to develop. Scanning is a type of rapid reading to get specific information or details. AbdulGhani believes students should learn how to apply scanning to find a specific piece of information in the material, and also be able to disregard the rest of information. ${ }^{15}$ Instructors should use texts that can be scanned in real life (e.g. an index), or prepare a task in which scanning will be useful; for instance, in the text

'Eating Plan Tips' students are asked to find information about 'poultry' that is mentioned in the text several times, so students browse through the reading and stop where they find the word 'poultry'. Then they skim this specific information. The instructor prepares questions about the information on 'poultry' to force the students to locate the information very rapidly, and answer the questions very rapidly, too.

Stoller suggests teaching students how to look for information very quickly by asking themselves questions that will withdraw information such as dates, times, countries, a place, capitalized words, or short phrases containing key words. One scanning activity can be to use the questions that teachers write at the end of the passage, specially those that ask for specific information. This author mentions that the questions can be directed to look for information in the whole text or in a paragraph and should be answered in a few minutes. ${ }^{16}$ Milne talks about the use of true or false questions for scanning. ${ }^{17}$ The use of both skimming and scanning develops confidence in the students. Learners come to realize that they do not have to understand everything to be able to understand and locate information.

15. S. Abdul-Ghani, "ESP reading: some implications for the design of materials," English Teaching Forum, 31, 4 (1993) 42-44.

16. F. Stoller, 2-7.

17. D. Milne, 37-38. 
In regard to structure, Day states that syntactic constructions do affect the readability of a passage. ${ }^{18}$ The study of difficult grammatical structures is something that can be taught before reading the text, but should be taught only if they will cause a communication breakdown. Teachers usually know what those structures are (e.g. in the case of Spanish speakers these would be: modals, have + past participles, -ing forms, noun phrases, passive constructions, there + be). Vasconcelos and Santiago suggest that in general the instructor should design exercises on language for each text. For the grammatical study, they propose the presentation of nominal phrases, verbs, clauses, reference words, etc. ${ }^{19}$

In a reading comprehension class, grammar must be viewed as a tool to communicate the message of the text, and should not be emphasized as a main concern. In these cases, the teacher isolates the structure and explains it using grammar exercises. For instance, one of the important structures to be taught for the text 'Eating Plan Tips' is "-ing". So what the teacher does is take advantage of this situation and teach all the uses of "-ing" and not just those that appear in the reading. $\mathrm{S} /$ he writes sentences on the board to explain all, or the most common and important possibilities of use of the specific structure under study. In Spanish, for example, “-ing” structures could be translated differently according to different grammatical functions: as a noun, adjective, verb(present and past), subordinate clause (presentand past), infinitive, past participle, and present participle. Later, the students will apply this knowledge when they find any "-ing" structures in the text while doing careful reading. And of course, they will keep on finding "-ing" structures in future texts, and the instructor will keep on pointing them out anytime they are encountered.

18. R. Day, "Selecting a passage for the EFL reading class," English Teaching Forum, 32, 1 (1994) 20-23.

19. J. De Vasconcelos \& V. Santiago, 36-37. 
Some educators prefer to teach grammar the way just mentioned; the grammar lesson first, and then the reading class. Others prefer to teach grammar during the reading activity and use the content of the reading to teach it. These two ways of teaching grammar have both advantages and disadvantages. For the first one, it is advantageous to teach all the possibilities of use of the structure at once using sentences, and then call the students' attention to the structure anytime it surfaces in the reading that is being studied, or in any future reading.

The drawback is that the sentences instructors use to teach the structure are not really a complete context; consequently, many clues (outside the sentence itself) that could help the reader understand the meaning are lost. Even though the second way of teaching is more holistic because grammar is taught in the text, it has a limitation too, the teacher can only teach and explain the structures that appear in the text. For instance, in the text "Eating Plan Tips' the "-ing" structures only exemplify “-ing” functioning as a noun, infinitive, adjective, and present participle. In any case, no matter if the teaching of grammar is done inductively or deductively, it should be taught one structure at a time, or one grammatical aspect per text. In this way the focus will mainly be on the content of the reading.

Another important element to understand a text is lexical knowledge or vocabulary. It is necessary to teach students basic vocabulary or those words that can be found in almost any text; for example, the, a, same, only, for, in, at, etc., and those other words that belong to each text and are topically related. There are certain strategies to get the meaning of these words if unknown. Learners scan the text looking for those words that are key to the content, but cannot be inferred easily from the context. Then they underline them or write them down on a separate piece of paper. These key words generally end up being recurrent in the text. Then they try to infer the meaning using clues, or ask a classmate or the teacher for the meanings.

One way of teaching students how to pick the important words is by imitating the instructor. At the beginning of the course, the teacher 
highlights or glosses key words and expressions in the text before the learners read it. This pedagogical practice helps students understand which important words contribute to the main meaning, and consequently, they will eventually learn how to do this same task by themselves. Thus, if the teachers are going to do this, Dubin believes they should ask themselves these questions: Are the words glossed words that the students have to learn? Are they just difficult words? Are they useful to get the main ideas in this particular text? After deciding what words to teach, introduce on the board the important ones in several sentences that provide a clear context, and explain them. The unimportant or useless ones should be mentioned and then discarded or ignored. ${ }^{20}$

Another way of facilitating lexical knowledge is providing some key words before reading the text, and asking them to look for a few others after skimming it. For instance, for the text 'Eating Plan Tips' the teacher can write on the board the words: cook, trim off, fat, bake, servings, meat, poultry, eat, and tip, and ask for their meanings. If none of the students knows the meanings the teacher provides them. The last two words of the list 'eat' and 'tip' appear in the title because the teacher will consider a priority to facilitate a clear idea of the title (since many times it provides the topic of the text). Later the students could underline others while skimming the text, and ask for their meanings. The purpose of this activity is to let the reader realize that they should look up only for some words, the important or key ones (those that relate to the topic of the text, or that are repeated), and not worry about all of the unknown words. They have to understand that they will recognize and learn more and more vocabulary each time they read a text (mainly so if they read on the same topic).

Sökmen suggests asking students to bring texts to class to make them responsible for the development of their own vocabulary, and

20. F. Dubin, "Learning new vocabulary through context: insights from materials preparation," Journal of Intensive English Studies, 3, Spring/Fall (1989). 
build up the vocabulary they might need for the reading of texts on similar topics later. The teacher can help by ranking these texts according to the difficulty of the vocabulary from easier to more difficult. $^{21}$

Educators should also teach students the most common affixes that appear in the readings which are not similar to those in their native language. Mastering the use or meaning of affixes helps a great deal the comprehension of any reading. For example, for the text 'Eating Plan Tips', teach $-y$ as an adjective marker, and -less as a negative adjective marker. At the beginning of the class, the instructor prepares sentences to explain these affixes, or may include them in the same sentences used to explain grammar, and call attention to the use of these specific affixes in the reading text during the in-reading stage. The teacher could also prepare a lesson on all adjective affixes and teach it before the reading activities start.

During the application of pre-reading strategies the dictionary is not allowed because this stage is just the first approach to the reading process. This will force the learners to infer the meanings by using all the means they have at hand (inference, morphology, cognates, explanations, and definitions that appear in the text, the context itself, etc.). If they still cannot guess the meanings the teacher will be there to supply any they may need (mainly those that refer to key words). The instructor must make it clear that the students do not need to know most of the unfamiliar vocabulary at this point (pre-reading).

\section{A ten-step pre-reading strategy guideline for the teacher}

1. Teach students the structure you believe may cause communication problems. Choose only one of the structures exemplified in the text and ignore other complex structures. Write sentences that illustrate the structure. Give the students practice on this specific

21. A. J. Sökmen, “Students as vocabulary generators," Tesol Journal, 2 (1992) 16-18. 
structure. Here grammar is only a tool for reading, so the structures must be considered message carriers and not be taken as production exercises. The teacher can also take advantage of the sentences to teach some other aspects such as morphology (e.g. affixes). The reading has not been handed out yet. Approximate time 30-45 minutes*

2. Ask questions about the topic of the reading to develop background knowledge or to bring back previous knowledge. The students have not seen the reading yet. Approximate time 5-7 minutes

3. Ask for the meanings of some key words. For instance, take out about six very important words that appear in the text and title, and write them down on the board. Ask if someone knows the meaning of those words. Since they already talked about the content of the reading in \#2 they may know or be able to infer the meanings. If some students know them, write the meanings down on the board. If nobody knows them, provide their meanings. Ask students to draw a semantic map with them (if possible) to establish a relationship among their meanings. This is a vocabulary preparation activity. The students have not seen the reading yet. Approximate time 5-10 minutes

4. Ask students what they believe the reading is about just by looking at the title, pictures, subheadings, underlining, boldfacing, charts, graphs, tables, etc. The text is handed out. This is the first time they take a brief look at the reading. At this point they are just observing and making very vague predictions. Approximate time 1 minute

5. Ask learners to skim the first and last paragraphs, and the first sentence of each intermediate paragraph. (This is a silent, and rapid-reading activity). Ask them what the text is about (topic and main idea(s)), and what other secondary ideas or details they understood. Any answer is fine because they are guessing information with the little information they have from doing skimming.Approximate time 2-3 minutes* The teacher will write

The approximate time depends on the length of the reading. The time span given here is for a one-page text. 
down on the board some ideas for the students to corroborate if they are right later on after careful reading is done. The instructor could also draw a graphic organizer with those ideas. Approximate time 5-7 minutes

6. If the text is notvery long ask them to read the whole reading very quickly (skimming). Time the reading process so that they do it really fast. Ask them what else they understood. Approximate time 2-3 minutes* Add the information to the one already on the board. Approximate time 5-10 minutes

7. Ask them to give you the pattern of organization of the reading. Is it a listing, cause-effect, time order, definition, classification, comparison-contrast, process, description text? (Any answer is fine because they are guessing information with the little information they have from doing skimming). The right answers will be corroborated when they do a more careful reading of the text. Approximate time 1 minute

8. The teacher can also ask about the tone, attitude, and purpose of the author in writing the text. The students must know the difference among those concepts beforehand. (Again any answer will be accepted because they are guessing information with the little information they have from doing skimming. The teacher will write down on the board some ideas and will verify them later after careful reading is done). Approximate time 2-3 minutes

9. Prepare some questions in which learners have to look for a specific piece of information such as a price, date, proper name, etc. This is called scanning. (This is a rapid-reading activity). Approximate time 2-3 minutes*

10. Ask students to read the text again very quickly. Ask them to underline important unknown words. Approximate time 2-3 minutes* Ask them which words are repeated in the text and seem to be key words. Write them down on the board. Add them to the ones the teacher had already given them. If someone knows the meanings write them on the board; if nobody knows them the 
teacher provides the meanings or asks students to guess them. Since they already know what the main ideas of the text are, they could infer some of them from the context. They cannot take out all the unknown words, only the key ones. Approximate time 5 minutes

To conclude, instructors should encourage a discussion among students of the importance of pre-reading strategies when reading a text in another language. On the other hand, the educators themselves have to understand that these strategies are preparation strategies for reading. So far the students have not read the reading carefully, they have not even done a normal-speed reading; consequently, the instructors have to respect and accept every single guess or inference the students make because at this stage all they are doing is predicting. It is very likely that after having applied pre-reading strategies a student at a beginning level may have understood that the text is about a plan or list of suggestions for a more healthy diet, and directed to a person with cholesterol problems. They may have given mistaken information (which is acceptable at this point). In this case, the teacher takes it into account and tells the class (in general) that the information will have to be verified later when they do a careful reading. After applying pre-reading strategies the learners will read the text more carefully, and more slowly for the first time, and at this point they will apply in-reading and then post-reading strategies. 